\title{
Factors Associated With Health-Related Quality of Life Among Older People Exposed to the Jeju 4.3 Incident
}

\author{
Moon-Doo Kim ${ }^{1}$ and Young-Eun Jung ${ }^{1,2} \bowtie$ \\ ${ }^{1}$ Department of Psychiatry, College of Medicine, Jeju National University, Jeju, Republic of Korea \\ ${ }^{2} 4 \cdot 3$ Trauma Center, Jeju, Republic of Korea
}

Objective We explored factors associated with health-related quality of life (HRQOL), including socio-demographic and clinical characteristics, in among older people exposed to the Jeju 4.3 incident, and aimed to determine the effects of depression, posttraumatic stress disorder (PTSD) and perceived social support on HRQOL.

Methods We obtained data from 110 survivors and 1,011 immediate family members of the victims of the Jeju April 3 incident (mean age, 75.1 years), and evaluated the relationships of HRQOL with sociodemographic and clinical characteristics including posttraumatic and depressive symptoms, and perceived social support.

Results Poorer physical health, psychological health, social relationships, and environment HRQOL domain scores were strongly associated with older age, being a woman, poor socioeconomic status, and symptoms of depression and PTSD. The regression analyses indicated that, when relevant factors were controlled for, perceived social support moderated the negative association between HRQOL and psychiatric symptoms.

Conclusion Our results suggest the importance of sociodemographic characteristics, in addition to psychiatric symptoms, for understanding HRQOL in older people exposed to the Jeju 4.3 incident. These results have important implications for interventions aiming to improve the HRQOL of the victims of the Jeju 4.3 incident.

Psychiatry Investig 2021;18(9):809-817

Keywords Jeju April 3 incident; Health-related quality of life; PTSD; Depression; Older people.

\section{INTRODUCTION}

The Jeju 4.3 incident (1948-1954) comprised a series of armed uprisings and counterinsurgencies that resulted in an estimated $15,000-30,000$ deaths (approximately $10 \%-15 \%$ of the population of Jeju Island at that time). ${ }^{1,2}$ The incident was systematically concealed from the general public over the last several decades, and little support, such as official recognition or financial or medical subsidies, have been offered to surviving victims or victims' families. ${ }^{1,2}$ Recently, two studies reported on the long-term psychological effects of the Jeju $4 \cdot 3$ incident and showed that, despite the fact that it took place 70 years ago, older people exposed to the Jeju $4 \cdot 3$ incident still

\section{Received: January 22, 2021 Revised: May 2, 2021}

Accepted: June 30, 2021

$\triangle$ Correspondence: Young-Eun Jung, MD, PhD

Department of Psychiatry, College of Medicine, Jeju National University, 15 Aran 13-gil, Jeju 63241, Republic of Korea

Tel: +82-64-754-8150, Fax: +82-64-717-1861, E-mail: jyejye@jejunu.ac.kr

(c) This is an Open Access article distributed under the terms of the Creative Commons Attribution Non-Commercial License (https://creativecommons.org/licenses/bync/4.0) which permits unrestricted non-commercial use, distribution, and reproduction in any medium, provided the original work is properly cited. suffer psychological sequelae related to the extreme stress that they encountered at that time. The risk of suicide was 7.55 times higher among survivors of the Jeju 4.3 incident than among a sample of community-dwelling older adults. ${ }^{3}$ Of the older survivors and victims' families of the Jeju 4.3 incident, $10.8 \%$ met the criteria for comorbid depression and posttraumatic stress disorder (PTSD), 3.0\% had PTSD only, and $24.3 \%$ had depression only. ${ }^{4}$ Compared to the lifetime prevalence of PTSD reported in general population surveys of older adults $(3 \%-5 \%),{ }^{5,6}$ older people exposed to the Jeju 4.3 incident were more than twice as likely to have PTSD.

The psychiatric conditions (PTSD, depression, and comorbid depression and PTSD) experienced by those who were exposed to this incident could reduce psychosocial functioning, role participation, and life satisfaction. Physical health, psychological health, social functioning, environment, and general life quality, i.e., health-related quality of life (HRQOL), ${ }^{7}$ could also be impaired. In older people, HRQOL may be an independent determinant of wellness and disease burden. ${ }^{8,9}$ Generally, the victims of the Jeju 4.3 incident may have difficulty adapting to the aging process, which is associated with 
changes in health status, functional competence, and the degree of dependence in daily life activities. Similarly, a study of aging Holocaust survivors reported lower HRQOL than compared to those who did not experience the Holocaust. ${ }^{10}$ Furthermore, 50 years after the Korean War, the HRQOL in older veterans was poor relative to other community samples. ${ }^{11}$

A large body of research has provided important information on the correlates of HRQOL in older people. Sociodemographic factors, such as age, gender, and marital status, as well as social and clinical factors, including social support, PTSD symptoms, and depression, are known to influence HRQOL. ${ }^{12-17}$ However, information regarding the correlates of HRQOL in older people with long-term psychological sequelae from extreme trauma is scarce. Among the large group of now-elderly individuals who experienced trauma during childhood, which might have caused psychological problems over the subsequent 70 years, ${ }^{3,4}$ those exposed to the Jeju $4 \cdot 3$ incident are of special interest for investigations of the relationships among traumatic experiences, long-term psychological problems such as depression, and other correlates of HRQOL. Moreover, identifying factors that protect against the negative effects of depression and PTSD symptoms could inform interventions and services aiming to improve HRQOL.

The current study was conducted to identify sociodemographic and clinical characteristics associated with HRQOL, including depression, PTSD symptoms, and perceived social support, in older people exposed to the Jeju 4.3 incident.

\section{METHODS}

\section{Study participants}

The Jeju 4.3 surviving victims and victims' immediate families (parents, siblings, spouse, and children) were identified from registry data obtained from the Jeju 4.3 Victims' Organization. Victims refer to "a person who died or went disappeared, suffers from the aftereffects, became disabled, or was convicted of a crime due to Jeju 4.3 incident". Victims and their immediate families have been identified by the Jeju 4.3 Incident Committee. A total of 158 surviving victims and 12,246 immediate family members of the victims were alive at the time of the survey (January 2015). All surviving victims ( $\mathrm{n}=$ 158) were eligible for this study. A total of 1,200 immediate family members of the victims were extracted via a stratified simple random sampling method. Of the 1,358 eligible people, 161 refused to participate, 41 experienced difficulties during their interviews because of impaired hearing or vision (and were thus excluded), and 35 could not be reached after four attempts. Ultimately, a total of 110 (69.2\%) surviving victims were included in the study; 59 were men, 51 were women, and the mean age was 83.4 years (standard deviation [SD]:
6.4 years, range: $68-99$ years). Their ages at the time of the traumatic experiences were as follows: $1-9$ years $12 / 110$ (10.9\%); $10-19$ years $51 / 110$ (46.4\%); and $20-32$ years $47 / 110$ (42.7\%). And, a total of 1,011 immediate family members of the victims (82.5\%) completed the interviews; 539 were men, 472 were women, and the mean age was 74.2 years (SD: 7.1 years, range: $58-99$ years).

\section{Ethical statement}

The study protocols were approved by the Institutional Review Board of Jeju National University Hospital, Korea (IRB No. JEJUNUH 2015-09-002).

\section{Assessments}

The survey included various self-report questionnaires that were orally administered by interviewers during in-person interviews. Data on sociodemographic and health-related characteristics were collected, including age, gender, duration of education, marital status, monthly household income, employment status, living arrangements, and history of chronic medical conditions.

To assess HRQOL, we administered the abbreviated (26item) version of the World Health Organization Quality of Life (WHOQOL-BREF) instrument, ${ }^{7}$ which consists of HRQOL items concerning respondents' views on various aspects of their lives, and how satisfactory or problematic these aspects are. The WHOQOL-BREF contains two items from the Overall QOL and General Health section and one item from each of the remaining 24 sections, which can be classified into four domains: physical health (7 items), psychological health (6 items), social relationships ( 3 items), and environment ( 8 items). All items are rated on a 5-point scale (1-5), with higher scores indicating better HRQOL. The Korean version of the WHOQOL-BREF has proven to be valid and reliable. ${ }^{18}$

To screen for depression, we employed the Korean version of the Center for Epidemiologic Studies-Depression scale (CESD). ${ }^{19}$ The CES-D is composed of 20 items that are scored from 0 (rarely or none of the time) to 3 (most or all of the time). Total scores range from 0 to 60 , with a higher score indicating more depressive symptoms. ${ }^{20}$ The PTSD Checklist-Civilian Version (PCL-C) was used to assess PTSD symptoms. The PCL-C is a 17 -item self-report questionnaire, and total scores range from 17 to 85 , with higher scores indicating more severe PTSD symptoms. ${ }^{21,22}$ Perceived social support was assessed using the Medical Outcomes Study Social Support Survey (MOS-SSS). This survey measures various aspects of perceived social support (emotional, informational, tangible, and affectionate support, and positive social interactions). The participants were asked to indicate how often each type of support was available to them if needed. All but one item (i.e., 
number of close friends or relatives) is rated on a Likert-type scale ranging from 1 to 5 ( $1=$ none of the time; $5=$ all of the time), with higher scores indicating greater perceived social support. ${ }^{23}$

\section{Statistical analysis}

For binary measures such as gender, group (survivors or family members), living arrangements (living alone or not), employment status (currently employed or unemployed), and chronic medical conditions (yes or no), we used an independent $\mathrm{t}$-test to compare mean WHOQOL-BREF scores. For discrete measures with more than two levels, such as marital status, duration of education, and monthly household income, we used analysis of variance to compare mean WHOQOLBREF scores among groups. To identify the relationships between WHOQOL-BREF scores and participant characteristics, we used Pearson's correlation analysis for continuous clinical and sociodemographic characteristics (e.g., age). Finally, to test the hypothesis that perceived social support modulates the association of QOL with symptoms of depression and PTSD, hierarchical regression analyses were conducted, adjusted for factors that were significantly associated with WHOQOL-BREF scores. In step 1 of the hierarchical linear regression analysis, symptoms of depression (CES-D) and PTSD (PCL-C) were included as predictors. Social support (MOS-SSS) was entered in step 2. All statistical analyses were performed using SPSS software (version 25.0; IBM Corp., Armonk, NY, USA), and $p$-values $<0.05$ were considered to indicate statistical significance.

\section{RESULTS}

Table 1 shows the sociodemographic and clinical characteristics. Of the 1,121 participants (110 surviving victims and 1,011 family members of victims) included in the analysis; 598 (53.3\%) were men, 523 (46.7\%) were women, and their mean age was 75.1 years (SD: 7.5 years, range: $58-100$ years). The Overall QOL and General Health WHOQOL-BREF score was $5.8 \pm 2.8$, while the physical health domain score was 20.4 (SD: 5.9), the psychological health domain score was 17.1 (SD: 4.5), the social relationships domain score was 9.5 (SD: 1.9), and the environment domain score was 22.9 (SD: 5.3).

Table 2 presents the associations between sociodemographic characteristics and WHOQOL-BREF scores. The results revealed significant group differences in HRQOL between the group, gender, education level, marital status, monthly household income, living arrangements, employment status, and chronic medical conditions groups. Lower scores in all WHOQOL-BREF domains were significantly associated with being a survivor, being a woman, having less education, being un-
Table 1. Characteristics of the study population

\begin{tabular}{|c|c|}
\hline Variables & $\mathrm{N}$ (\% of subjects) \\
\hline \multicolumn{2}{|l|}{ Group } \\
\hline Surviving victims & $110(9.8)$ \\
\hline Victims' families & $1,011(90.2)$ \\
\hline Gender (men) & $598(53.3)$ \\
\hline \multicolumn{2}{|l|}{ Education levels, y } \\
\hline$\leq 6$ & $677(60.4)$ \\
\hline $7-12$ & $376(33.5)$ \\
\hline$\geq 13$ & $68(6.1)$ \\
\hline \multicolumn{2}{|l|}{ Marital status } \\
\hline Married & $745(66.5)$ \\
\hline Never married & $20(1.8)$ \\
\hline Widowed & $330(29.4)$ \\
\hline Divorced/separated & $26(2.3)$ \\
\hline \multicolumn{2}{|l|}{ Monthly household income, US\$ } \\
\hline$<1,000$ & $686(61.2)$ \\
\hline $1,000-2,990$ & $359(32.0)$ \\
\hline$\geq 3,000$ & $76(6.8)$ \\
\hline Living alone & $218(19.4)$ \\
\hline Employed state & $209(25.9)$ \\
\hline \multirow[t]{2}{*}{ Chronic medical conditions } & $942(84.0)$ \\
\hline & Mean (SD) \\
\hline Age, y & $75.1(7.5)$ \\
\hline CES-D & $16.4(11.8)$ \\
\hline PCL-C & $33.9(12.9)$ \\
\hline MOS-SSS & $65.0(13.5)$ \\
\hline \multicolumn{2}{|l|}{ WHQOL-BREF } \\
\hline Overall QOL \& general health & $5.8(2.8)$ \\
\hline Domain 1 physical health & $20.4(5.9)$ \\
\hline Domain 2 psychological health & $17.1(4.5)$ \\
\hline Domain 3 social relationships & $9.5(1.9)$ \\
\hline Domain 4 environment & $22.9(5.3)$ \\
\hline
\end{tabular}

CES-D, the Center for Epidemiologic Studies Depression Scale; MOS-SSS, the Medical Outcomes Study Social Support Survey; PCL-C, The PTSD Checklist-civilian version; QOL, quality of life; WHOQOL-BREF, the 26-item abbreviated version of the World Health Organization Quality of Life assessment instrument; SD, standard deviation

married, having a low monthly household income, living alone, being unemployed, and having chronic medical conditions. For the surviving victims $(n=110)$, there were no significant differences in HRQOL among groups in terms of age at the traumatic experience. Table 3 also shows that lower scores for all WHOQOL-BREF domains were associated with greater symptom severity (higher scores on the CES-D and PCL-C) (each, $\mathrm{p}<0.001$ ). Conversely, greater perceived social support 


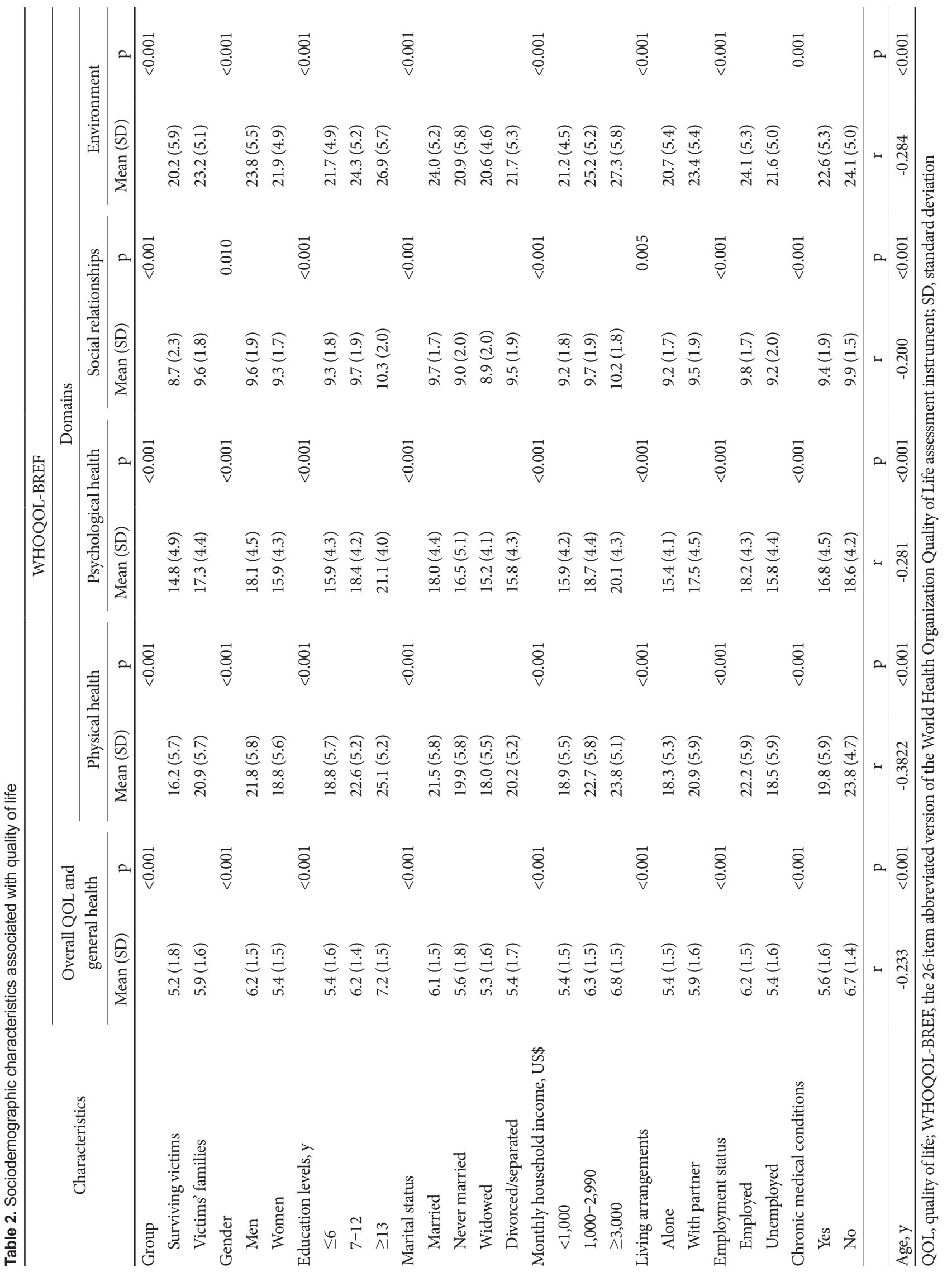


Table 3. Clinical characteristics associated with quality of life

\begin{tabular}{|c|c|c|c|c|c|c|c|c|c|c|}
\hline \multirow{4}{*}{ Characteristics } & \multicolumn{10}{|c|}{ WHOQOL-BREF } \\
\hline & \multirow{2}{*}{\multicolumn{2}{|c|}{$\begin{array}{l}\text { Overall QOL and } \\
\text { general health }\end{array}$}} & \multicolumn{8}{|c|}{ Domains } \\
\hline & & & \multicolumn{2}{|c|}{ Physical health } & \multicolumn{2}{|c|}{ Psychological health } & \multicolumn{2}{|c|}{ Social relationships } & \multicolumn{2}{|c|}{ Environment } \\
\hline & $\mathrm{r}$ & $\mathrm{p}$ & $\mathrm{r}$ & $\mathrm{p}$ & $\mathrm{r}$ & $\mathrm{p}$ & $\mathrm{r}$ & $\mathrm{p}$ & $\mathrm{r}$ & $\mathrm{p}$ \\
\hline CES-D & -0.508 & $<0.001$ & -0.584 & $<0.001$ & -0.598 & $<0.001$ & -0.355 & $<0.001$ & -0.499 & $<0.001$ \\
\hline PCL-C & -0.356 & $<0.001$ & -0.438 & $<0.001$ & -0.400 & $<0.001$ & -0.221 & $<0.001$ & -0.325 & $<0.001$ \\
\hline MOS-SSS & 0.132 & $<0.001$ & 0.179 & $<0.001$ & 0.219 & $<0.001$ & 0.345 & $<0.001$ & 0.288 & $<0.001$ \\
\hline
\end{tabular}

CES-D, the Center for Epidemiologic Studies Depression Scale; MOS-SSS, the Medical Outcomes Study Social Support Survey; PCL-C, the PTSD Checklist-civilian version; QOL, quality of life; WHOQOL-BREF, the 26-item abbreviated version of the World Health Organization Quality of Life assessment instrument

was associated with higher scores in all HRQOL domains ( $\mathrm{p}<$ $0.001)$.

The results of hierarchical regression analyses are presented in Table 4. After controlling for relevant factors (exposure type, gender, age, marital status, monthly household income, employment status, living arrangements, and chronic medical conditions), depressive symptoms (CES-D) and PTSD symptoms (PCL-C) were entered simultaneously into the HRQOL regression model (step 1). Depressive symptoms were negatively associated with all HRQOL domain scores, whereas PTSD symptoms had no or weak associations. The depression and PTSD symptoms together accounted for $36.1 \%$ of the variance in overall QOL and general health, $47.3 \%$ of the variance in physical health, $44.3 \%$ of the variance in psychological health, $15.5 \%$ of the variance in social relationships, and $36.6 \%$ of the variance in the environment domain. Perceived social support was positively associated with all HRQOL domains scores after controlling for relevant factors. When entered after demographic characteristics, symptoms of depression and PTSD, and perceived social support (MOS-SSS) as covariates in the final regression analysis (step 2), perceived social support was positively associated with all HRQOL domain scores. This model (step 2) explained an additional $7.4 \%$ of the variance in social relationships, and an additional $2.7 \%$ of the variance in the environment domain, indicating that perceived social support modulated the associations of HRQOL with symptoms of depression and PTSD.

\section{DISCUSSION}

In this study, we aimed to assess the impact of depression, PTSD symptoms, and perceived social support and various sociodemographic characteristics on the HRQOL of older people exposed to the Jeju 4.3 incident.

We found that poorer physical health, psychological health, social relationships, and environment HRQOL domain scores were all associated with more severe psychiatric symptoms, including depression and PTSD symptoms. This is consistent with a number of other studies that have identified associations between current psychiatric symptoms and many aspects of HRQOL in elderly populations. ${ }^{13,14,24-27}$ More severe depressive symptoms were associated with poorer HRQOL among elderly people. ${ }^{13,25-27}$ Depression among elderly people can undermine their sense of purpose, making their existence seem meaningless. It might also result in a lack of interest in life, less satisfying social interactions, and low activity levels accompanied by physical decline. ${ }^{28}$ Ultimately, depression may significantly reduce HRQOL during aging. Furthermore, PTSD symptoms in older people have an independent negative effect on HRQOL, even after controlling for comorbid depression. ${ }^{14,29}$ Therefore, the detection and treatment of depression and PTSD symptoms is very important to improve HRQOL in older people exposed to the Jeju 4.3 incident.

The current results showed that some sociodemographic factors, such as age, gender, education level, monthly household income, employment status, marital status, and living arrangements, were associated with HRQOL. We observed that women had significantly poorer HRQOL in all domains compared to men. In general, older Korean women have less access to information and education, and a lower overall economic status and social position compared to men. Similarly, previous studies of HRQOL have found that women were disadvantaged compared to men, which was related to gender differences in social roles and physiological and psychological factors. ${ }^{30,31}$ Improving women's HRQOL requires a multidisciplinary, culturally appropriate approach, to create a better living environment.

In addition, HRQOL was strongly associated with greater socioeconomic resources among older people exposed to the Jeju 4.3 incident, including higher education levels, fewer financial difficulties, and current employment. The present study also showed that HRQOL was better in elderly people living with others compared to those living alone. Likewise, married older people enjoyed a higher HRQOL than those who were never married, or were widowed or divorced. Additionally, the presence of chronic medical conditions, which can cause many 
Table 4. Hierarchical regression analysis of factors associated with quality of life

\begin{tabular}{|c|c|c|c|c|c|c|}
\hline \multirow{2}{*}{ WHOQOL-BREF } & \multicolumn{3}{|c|}{ Step $1^{\text {a }}$} & \multicolumn{3}{|c|}{ Step $2^{\mathrm{a}}$} \\
\hline & $\mathrm{B}$ & $\beta$ & $\mathrm{t}$ & $\mathrm{B}$ & $\beta$ & $\mathrm{t}$ \\
\hline \multicolumn{7}{|l|}{ Overall QOL and general health } \\
\hline CES-D & -0.052 & -0.384 & $-11.601^{* * *}$ & -0.051 & -0.375 & $-11.011^{* * *}$ \\
\hline PCL-C & -0.001 & -0.005 & -0.150 & -0.001 & -0.008 & -0.256 \\
\hline MOS-SSS & & & & 0.004 & 0.031 & 1.238 \\
\hline Adjusted $\mathrm{R}^{2}$ & 0.361 & & & 0.362 & & \\
\hline Adjusted $\mathrm{R}^{2}$ change & & & & 0.001 & & \\
\hline $\mathrm{F}$ & $64.148^{* * *}$ & & & $58.484^{* * *}$ & & \\
\hline \multicolumn{7}{|l|}{ Physical health } \\
\hline CES-D & -0.209 & -0.417 & $-13.858^{* * *}$ & -0.199 & -0.397 & $-12.881^{* * *}$ \\
\hline PCL-C & -0.017 & -0.038 & -1.273 & -0.021 & -0.045 & -1.515 \\
\hline MOS-SSS & & & & 0.028 & 0.064 & $2.839^{*}$ \\
\hline Adjusted $\mathrm{R}^{2}$ & 0.473 & & & 0.477 & & \\
\hline Adjusted $\mathrm{R}^{2}$ change & & & & 0.004 & & \\
\hline $\mathrm{F}$ & $101.444^{* * *}$ & & & $93.540^{* * *}$ & & \\
\hline \multicolumn{7}{|l|}{ Psychological health } \\
\hline CES-D & -0.196 & -0.510 & $-16.486^{* * *}$ & -0.185 & -0.483 & $-15.280^{* * *}$ \\
\hline PCL-C & 0.013 & 0.037 & 1.200 & 0.009 & 0.027 & 0.882 \\
\hline MOS-SSS & & & & 0.029 & 0.087 & $3.759^{* * *}$ \\
\hline Adjusted $\mathrm{R}^{2}$ & 0.443 & & & 0.450 & & \\
\hline Adjusted $\mathrm{R}^{2}$ change & & & & 0.007 & & \\
\hline $\mathrm{F}$ & $89.905^{* * *}$ & & & $83.983^{* * *}$ & & \\
\hline \multicolumn{7}{|l|}{ Social relationships } \\
\hline CES-D & -0.053 & -0.334 & $-8.766^{* * *}$ & -0.039 & -0.245 & $-6.560^{* * *}$ \\
\hline PCL-C & 0.009 & 0.062 & 1.653 & 0.004 & 0.030 & 0.840 \\
\hline MOS-SSS & & & & 0.039 & 0.284 & $10.344^{* * *}$ \\
\hline Adjusted $\mathrm{R}^{2}$ & 0.155 & & & 0.229 & & \\
\hline Adjusted $\mathrm{R}^{2}$ change & & & & 0.074 & & \\
\hline $\mathrm{F}$ & $21.537^{* * *}$ & & & $31.177^{* * *}$ & & \\
\hline \multicolumn{7}{|l|}{ Environment } \\
\hline CES-D & -0.193 & -0.428 & $-12.991^{* *}$ & -0.169 & -0.375 & $-11.297^{* * *}$ \\
\hline PCL-C & 0.031 & 0.075 & $2.312^{*}$ & 0.023 & 0.056 & 1.748 \\
\hline MOS-SSS & & & & 0.068 & 0.172 & $7.089^{* * *}$ \\
\hline Adjusted $\mathrm{R}^{2}$ & 0.366 & & & 0.393 & & \\
\hline Adjusted $\mathrm{R}^{2}$ change & & & & 0.027 & & \\
\hline $\mathrm{F}$ & $65.790^{* * *}$ & & & $67.031^{* * *}$ & & \\
\hline
\end{tabular}

${ }^{*} \mathrm{p}<0.05 ;{ }^{* *} \mathrm{p}<0.01 ;{ }^{* * *} \mathrm{p}<0.001 .{ }^{a}$ adjustment for exposure type, gender, age (per year), marital status, monthly household income, employment state, living arrangement, and chronic medical conditions. CES-D, the Center for Epidemiologic Studies Depression Scale; MOS-SSS, the Medical Outcomes Study Social Support Survey; PCL-C, The PTSD Checklist-civilian version; QOL, quality of life; WHOQOL-BREF, the 26-item abbreviated version of the World Health Organization Quality of Life assessment instrument

problems such as poor self-care, pain, lack of sleep, and a restricted social life, was negatively related to all HRQOL domains. Prior research has also found that many demographic and clinical factors, such as occupation, income, marital sta- tus, education, medical conditions, and feeling of loneliness, predicted differences in various HRQOL domains among older people. ${ }^{32-35}$ Satisfactory socioeconomic status, health status, and social relationships are important for a good HRQOL, 
not only to meet basic needs, but also to reduce worry about emergencies and ensure that emotional and practical support are available.

The most notable finding of this study was that the level of perceived social support was the factor most strongly associated with HRQOL in our sample of older people exposed to the Jeju 4.3 incident. When all significant variables, including socio-demographic factors, depression, and PTSD symptoms, were included in the stepwise regression model, perceived social support modulated the negative relationships between HRQOL and symptoms of depression and PTSD in the final model. This is consistent with previous studies of elderly populations. The study of Chan et al. ${ }^{36}$ on elderly Chinese patients with depression showed that social support predicted higher HRQOL after controlling for depressive symptom severity. Among elderly patients with heart failure, social support was important for reducing depressive symptoms and maintaining HRQOL. ${ }^{37}$ A study of older veterans found that social support moderated the associations of PTSD and depressive symptoms with HRQOL. ${ }^{38}$ In studies of elderly populations, social support has been conceptualized in many ways, ranging from simple structural support (according to living arrangements, family structure, and social network size) to complex combinations of structural and functional support (e.g., provision of emotional support to others, receipt of tangible support from others, and relationship to healthcare providers), and has also been linked to both psychological and physical health..$^{39-41}$ Moreover, post-trauma outcomes and social support may have implications beyond HRQOL. In previous studies of traumaexposed adults, high perceived social support was related to less severe depression and PTSD symptoms, ${ }^{42-44}$ greater overall psychological resilience, ${ }^{45}$ and better physical health outcomes. ${ }^{46}$

This finding highlights the need for healthcare providers and policymakers to develop strategies for managing the mental health of trauma-exposed groups. In particular, a better understanding of the modulatory role of perceived social support in the relationships of depression and PTSD symptoms with HRQOL will facilitate identification of sources of support that could help to enhance the HRQOL of older people with psychiatric symptoms who have been exposed to trauma.

The limitations of this study were as follows. First, this was a cross-sectional study, so it was not possible to draw definitive conclusions regarding the causal relationships among the various predictor variables and HRQOL. Second, the self-report measures of PTSD and depression symptoms used in the present study may lack precision, although the CES-D and PCL-C show good psychometric properties. ${ }^{20,21}$ Moreover, although individuals who had difficulty participating in the interview due to cognitive impairment or severe health problems were excluded from the analyses, the presence of cognitive im- pairments was not evaluated using standardized diagnostic tools. Third, the present study enrolled a unique population, i.e., older individuals who lived through the Jeju 4.3 incident in Korea. This population experienced a very specific trauma, so the present results may not be fully generalizable to other elderly populations.

Previous studies evaluating the HRQOL of older people exposed to trauma were carried out mainly with veterans or patients. ${ }^{11,14,29,38}$ Little is known about the psychosocial factors such as depression, PTSD, and perceived social support and their effect on the HRQOL among community-dwelling older people with traumatic experiences. Our findings show that older age, being a woman, poor socioeconomic status, and more severe psychiatric symptoms, including of depression and PTSD, were related to HRQOL in older people exposed to the Jeju $4 \cdot 3$ incident. We also found that perceived social support modulated the negative association between HRQOL and psychiatric symptoms. The present findings have important practical implications with respect to interventions for older people experiencing psychiatric problems due to encountering extreme stress in earlier stages of life. To prevent or reduce the ongoing suffering of this high-risk group, we emphasize that mental health service providers and policymakers should implement a multifaceted approach to improve perceived social support and reduce psychiatric symptoms, and thereby improve HRQOL.

\section{Availability of Data and Material}

The datasets generated or analyzed during the study are available from the corresponding author on reasonable request.

\section{Conflicts of Interest}

The authors have no potential conflicts of interest to disclose.

\section{Author Contributions}

Conceptualization: Moon-Doo Kim, Young-Eun Jung. Data curation: Moon-Doo Kim. Formal analysis: Young-Eun Jung. Investigation: MoonDoo Kim. Methodology: Moon-Doo Kim. Writing_original draft: YoungEun Jung. Writing-review \& editing: Moon-Doo Kim.

\section{ORCID iDs}

Moon-Doo Kim https://orcid.org/0000-0002-6441-630X

Young-Eun Jung https://orcid.org/0000-0001-7608-0009

\section{Funding Statement \\ None.}

\section{Acknowledgments}

Special thanks to colleagues in the Jeju 4.3 Peace Foundation and 4.3 Trauma center.

\section{REFERENCES}

1. Jeju Peace Foundation. A guide to the history of the Jeju $4 \cdot 3$ incident; 2016. Available at: http://www.jejupeaceacademy.com/manual.pdf . Accessed March 1, 2021. 
2. Yang JS, Kang DH, Park CS, Cho JH. The Jeju 4.3 Incident Follow-up Investigation Report I. Jeju: Jeju 4.3 Peace Foundation; 2019.

3. Jung YE, Kim MD. Lifetime suicidal attempts and current suicidal risk in aging survivors of the Jeju April 3 incident. J Affect Disord 2018;225: 1-3.

4. Jung YE, Kim MD. Prevalence and correlates of comorbid PTSD with depression among older people exposed to the Jeju April 3 incident. J Affect Disord 2020;272:8-14.

5. Pietrzak RH, Goldstein RB, Southwick SM, Grant BF. Psychiatric comorbidity of full and partial posttraumatic stress disorder among older adults in the United States: results from wave 2 on the national epidemiologic survey on alcohol and related conditions. Am J Geriatr Psychiatry 2012;20:380-390.

6. Glaesmer H, Gunzelmann T, Braehler E, Forstmeier S, Maercker A. Traumatic experiences and post-traumatic stress disorder among elderly Germans: results of a representative population-based survey. Int Psychogeriatr 2010;22:661-670.

7. Development of the World Health Organization WHOQOL-BREF quality of life assessment. The HRQOL group. Psychol Med 1998;28: 551-558.

8. Bowling A. Aging Well, Quality of Life in Older Age. First Edition. Maidenhead: Open University Press; 2005.

9. Farquhar M. Elderly people’s definitions of quality of life. Soc Sci Med 1995;41:1439-1446.

10. Amir M, Lev-Wiesel R. Time does not heal all wounds: quality of life and psychological distress of people who survived the holocaust as children 55 years later. J Trauma Stress 2003;16:295-299.

11. Ikin JF, Sim MR, McKenzie DP, Horsley KW, Wilson EJ, Harrex WK, et al. Life satisfaction and quality in Korean War veterans five decades after the war. J Epidemiol Community Health 2009;63:359-365.

12. Gallicchio L, Hoffman SC, Helzlsouer KJ. The relationship between gender, social support, and health-related quality of life in a communitybased study in Washington County Maryland. Qual Life Res 2007;16: 777-786.

13. Layte R, Sexton E, Savva G. Quality of life in older age: evidence from an Irisch cohort study. J Am Geriatr Soc 2013;61(Suppl 2):S299-S305.

14. Chopra MP, Zhang H, Pless Kaiser A, Moye JA, Llorente MD, Oslin DW, et al. PTSD is a chronic, fluctuating disorder affecting the mental quality of life in older adults. Am J Geriatr Psychiatry 2014;22:86-97.

15. Bilgili N, Arpaci F. Quality of life in older adults in Turkey. Arch Gerontol Geriatr 2014;59:415-421.

16. Vanleerberghe P, De Witte N, Claes C, Schalock RL, Verté D. The quality of life of older people aging in place: a literature review. Qual Life Res 2017;26:2899-2907.

17. Kim GM, Hong MS, Noh W. Factors affecting the health-related quality of life in community-dwelling elderly people. Public Health Nurs 2018;35:482-489.

18. Min SK, Kim KI, Lee CI, Jung YC, Suh SY, Kim DK. Development of the Korean versions of WHO Quality of Life scale and WHOQOL-BREF. Qual Life Res 2002;11:593-600.

19. Cho MJ, Kim KH. Use of the Center for Epidemiologic Studies Depression (CES-D) Scale in Korea. J Nerv Ment Dis 1998;186:304-310.

20. Roberts RE, Rhoades HM, Vernon SW. Using the CES-D scale to screen for depression and anxiety: Effects of language and ethnic status. Psychiatry Res 1990;31:69-83.

21. Weathers F, Litz B, Huska J, Keane T. PTSD Checklist-Civilian Version. Boston: Nation Center for PTSD. Behavioral Sciences Division; 1994.

22. Oh SI, Won SD, Lee SH, Yoo SY, Kim HC, Kim HJ. Reliability and validity of the Korean version of the PTSD Checklist civilian version in North Korean defectors. J Korean Neuropsychiatr Assoc 2014;53:410417.

23. Sherbourne CD, Stewart AL. The MOS social support survey. Soc Sci Med 1991;32:705-714.

24. Schreiber S, Soskolne V, Kozohovitch H, Deviri E. Holocaust survivors coping with open heart surgery decades later: posttraumatic symptoms and quality of life. Gen Hosp Psychiatry 2004;26:443-452.

25. Zaninotto P, Falaschetti E, Sacker A. Age trajectories of quality of life among older adults: results from the English Longitudinal Study of Ageing. Qual Life Res 2009;18:1301-1309.

26. Brown PJ, Roose SP. Age and anxiety and depressive symptoms: the effect on domains of quality of life. Int J Geriatr Psychiatry 2011;26:12601266.

27. Doraiswamy PM, Khan ZM, Donahue RM, Richard NE. Quality of life in geriatric depression: A comparison of remitters, partial responders and non-responders. Am J Geriatr Psychiatry 2001;9:423-428.

28. Cole MG, Dendukuri N. Risk factors for depression among elderly community subjects: a systematic review and meta-analysis. Am J Psychiatry 2003;160:1147-1156.

29. Richardson JD, Long ME, Pedlar D, Elhai JD. Posttraumatic stress disorder and health-related quality of life in pension-seeking Canadian World War II and Korean War veterans. J Clin Psychiatry 2010;71:10991101.

30. Orfila F, Ferrer M, Lamarca R, Tebe C, Domingo-Salvany A, Alonso J. Gender differences in health-related quality of life among the elderly: the role of objective functional capacity and chronic conditions. Soc Sci Med 2006;63:2367-2380.

31. Kirchengast S, Haslinger B. Gender differences in health-related quality of life among healthy aged and old-aged Austrians: Cross-sectional analysis. Gend Med 2008;5:270-278.

32. Doraiswamy PM, Khan ZM, Donahue RM, Richard NE. The spectrum of quality-of-life impairments in recurrent geriatric depression. J Gerontol A Biol Sci Med Sci 2002;57:134-137.

33. Avis NE, Assmann SF, Kravitz HM, Ganz PA, Ory M. Quality of life in diverse groups of midlife women: assessing the influence of menopause, health status and psychosocial and demographic factors. Qual Life Res 2004;13:933-946.

34. Martikainen P, Stansfeld S, Hemingway H, Marmot M. Determinants of socioeconomic differences in change in physical and mental functioning. Soc Sci Med 1999;49:499-507.

35. Wensing M, Vingerhoets E, Grol R. Functional status, health problems, age and comorbidity in primary care patients. Qual Life Res 2001;10:141148.

36. Chan S, Jia S, Chiu H, Chien WT, Thompson DR, Hu Y, et al. Subjective health-related quality of life of Chinese older persons with depression in Shanghai and Hong Kong: Relationship to clinical factors, level of functioning and social support. Int J Geriatr Psychiatry 2009;24:355362.

37. Heo S, Lennie TA, Moser DK, Kennedy RL. Types of social support and their relationships to physical and depressive symptoms and health-related quality of life in patients with heart failure. Heart Lung 2014;43: 299-305.

38. Painter JM, Gray K, McGinn MM, Mostoufi S, Hoerster KD. The relationships of posttraumatic stress disorder and depression symptoms with health-related quality of life and the role of social support among Veterans. Qual Life Res 2016;25:2657-2667.

39. Lett HS, Blumenthal JA, Babyak MA, Catellier DJ, Carney RM, Berkman LF, et al. Social support and prognosis in patients at increased psychosocial risk recovering from myocardial infarction. Health Psychol 2007;26:418-427.

40. Sultan S, Fisher DA, Voils CI, Kinney AY, Sandler RS, Provenzale D. Impact of functional support on health-related quality of life in patients with colorectal cancer. Cancer 2004;101:2737-2743.

41. Seeman TE. Health promoting effects of friends and family on health outcomes in older adults. Am J Health Promot 2000;14:362-370.

42. Southwick SM, Vythilingam M, Charney DS. The psychobiology of depression and resilience to stress: Implications for prevention and treatment. Annu Rev Clin Psychol 2005;1:255-291.

43. Brewin CR, Andrews B, Valentine JD. Meta-analysis of risk factors for posttraumatic stress disorder in trauma-exposed adults. J Consult Clin 
Psychol 2000;68:748-766.

44. Ozer EJ, Best SR, Lipsey TL, Weiss DS. Predictors of posttraumatic stress disorder and symptoms in adults: a meta-analysis. Psychol Bull 2003; 129:52-73.

45. Pietrzak RH, Cook JM. Psychological resilience in older U.S. veterans: Results from the national health and resilience in veterans study. De- press Anxiety 2013;30:432-443.

46. Richmond NL, Meyer ML, Hollowell AG, Isenberg EE, Domeier RM, Swor RA, et al. Social support and pain outcomes after trauma exposure among older adults: a multicenter longitudinal study. Clin J Pain 2018;34:366-374. 